\title{
Arthroderma fulvum
}

National Cancer Institute

\section{Source}

National Cancer Institute. Arthroderma fulvum. NCI Thesaurus. Code C127683.

A species of geophilic fungi in the phylum Ascomycota with thin-walled, elongate,

ellipsoidal macroconidia having 3 to 6 septa. 